Submission to "Special issue: New Materials for Nuclear (Journal of Nuclear Materials)"

\title{
A review of advantages of high-efficiency X-ray spectrum imaging for analysis of nanostructured ferritic alloys
}

Chad M. Parish* and Michael K. Miller

Microscopy Group, Oak Ridge National Laboratory, Oak Ridge, TN, 37931, USA

* Email parishcm@ornl.gov, phone 18655740092

\begin{abstract}
Nanostructured ferritic alloys (NFAs) exhibit complex microstructures consisting of 100$500 \mathrm{~nm}$ ferrite grains, grain boundary solute enrichment, and multiple populations of precipitates and nanoclusters (NCs). Understanding these materials' excellent creep and radiation-tolerance properties requires a combination of multiple atomic-scale experimental techniques. Recent advances in scanning transmission electron microscopy (STEM) hardware and data analysis methods have the potential to revolutionize nanometer to micrometer scale materials analysis. Modern high-brightness, high-X-ray collection STEM instruments are capable of enabling advanced experiments, such as simultaneous energy dispersive X-ray spectroscopy and electron energy loss spectroscopy spectrum imaging at $\mathrm{nm}$ to sub-nm resolution, that are now wellestablished for the study of nuclear materials. In this paper, we review past results and present new results illustrating the effectiveness of latest-generation STEM instrumentation and data analysis.
\end{abstract}

Notice: This manuscript has been authored by UT-Battelle, LLC, under Contract No. DE-AC05-00OR22725 with the U.S. Department of Energy. The United States Government retains and the publisher, by accepting the article for publication, acknowledges that the United States Government retains a non-exclusive, paid-up, irrevocable, world-wide license to publish or reproduce the published form of this manuscript, or allow others to do so, for United States Government purposes. 


\section{Introduction}

Nanostructured ferritic alloys (NFAs) are among the materials under study for high-dose applications in future fission or fusion reactor concepts [1-7]. In particular, NFAs are found to have surprisingly good high-temperature creep properties despite their ultrafine grain size [8], and further studies of the microstructure, both intragranular and grain boundary, are needed to understand the origin of these properties. These NFA materials, such as the 14YWT alloy studied here, have a complex non-equilibrium microstructure produced by mechanical alloying and extrusion. Previous work [9-13] has indicated the microstructure consists of a ferritic matrix with a grain size of $\sim 100-500 \mathrm{~nm}$, with strong enrichment of $\mathrm{Cr}$ and $\mathrm{W}$ solutes at the grain boundaries over a width of $\sim 1.5 \mathrm{~nm}$ [14]. Titanium oxycarbonitride $(\mathrm{Ti}(\mathrm{O}, \mathrm{C}, \mathrm{N}))$ precipitates of $\sim 20-75 \mathrm{~nm}$ size are also found in the microstructure. In addition, finer $\mathrm{Ti}_{2} \mathrm{Y}_{2} \mathrm{O}_{7}$ precipitates and $\mathrm{Ti}-\mathrm{Y}-\mathrm{O}-$ enriched nanoclusters (NCs) are present both within the matrix grains and along the grain boundaries [7, 15-18]. Helium irradiations indicate significant sequestration of bubbles at the NCs [19-22].This combination of a complex, multi-length-scale microstructure with important engineering applications makes NFAs (specifically 14YWT) a materials system that would benefit from new structural analysis methodologies.

Transmission electron microscopy methods, particularly analytical electron microscopy (AEM) performed in scanning transmission (STEM) mode, complements scanning electron microscopy (SEM) and atom probe tomography (APT) by providing spatial resolutions, size scales, and minimum detectable mass and minimum mass fraction levels that lie in between those of SEM and APT. AEM methods are often used to analyze nuclear materials, such as NFAs, at a resolution of 0.5-5 nm. Energy filtered TEM (EFTEM) and spectrum imaging (SI) in electron energy loss spectroscopy (EELS) or energy dispersive X-ray spectroscopy (EDS) are used to identify small precipitates or grain boundary enrichments that are invisible to SEM, but not with the precision, accuracy, or spatial resolution of APT.

AEM characterization is limited by a number of factors. First, with a non-aberrationcorrected [23] instrument, typical probe sizes containing analytically useful currents (broadly $\sim 0.1-10 \mathrm{nA}$ ) will be $\sim 0.5-10 \mathrm{~nm}$, even on a field-emission instrument [24], which will establish a lower limit on spatial resolution. In addition, when microstructural features are smaller than the probe size, or when the features are embedded within the thickness of the specimen, the detection limits in EDS or EELS will be degraded due to signal arising from the matrix surrounding the feature of interest. Significantly smaller probe sizes are achievable at a given current via probe aberration correction [25], but for a feature within a thicker foil, the smaller probe will not necessarily result in improved spatial resolution and concomitantly improved detectability. Using standard equations (detailed in Appendix A), the EDS spatial resolution in STEM mode can be estimated as a function of the specific sample material, beam energy, probe size, and specimen thickness. Calculations for the spatial resolution for $200 \mathrm{keV}$ primary beam energy incident on an iron sample as a function of specimen thickness and probe size are shown in Figure 1a [19]. Increasing either the incident probe size or the specimen thickness significantly degrade the EDS spatial resolution. Somewhat thicker specimens provide more detector counts per unit beam current, allowing shorter acquisition times and reduced specimen electron dose. The probe size also varies with probe current, reducing the counts per unit time at smaller probe sizes. These tradeoffs can be visualized in reference to Figure 1a; a thicker specimen with a larger probe will have poorer spatial resolution, and vice-versa.

Recent advances in AEM hardware have resulted in commercially available systems that 
can provide $\sim 0.9$ srad solid angle of collection by integrating four discrete silicon drift detectors (SDDs) into the objective lens region of an AEM [26-28], compared to traditional STEM-EDS systems that typically collect $\sim 0.1$ srad. Combining high-brightness sources now available, approximately $5 \times$ brighter than traditional Schottky emitters with advanced data post-processing techniques, a modern AEM is capable of greatly improved materials analysis and more readily explain structure-property relationships, such as the nature of grain boundaries in 14YWT and their relation to creep. When an advanced AEM instrument, such as the FEI Tecnai Osiris, is compared to a more traditional Philips CM200 (both are $200 \mathrm{keV}$ analytical SchottkyTEM/STEM instruments), values calculated for STEM-EDS resolution at a given EDS count rate (Appendix A) are $\sim 3.3 \mathrm{~nm}$ resolution for a conventional AEM with a $2 \mathrm{~nm}$ probe and a $100 \mathrm{~nm}$ foil, compared to $\sim 1.0 \mathrm{~nm}$ resolution for the advanced AEM with $0.9 \mathrm{~nm}$ probe and a $14 \mathrm{~nm}$ foil (Figure 1a). Smaller improvements in spatial resolution could be balanced against vastly improved count rates by using similarly sized probes and samples of lesser thickness differences. With focused ion beam (FIB)-based specimen preparation now becoming standard, adjusting specimen thicknesses for the experimental conditions is trivial. However, recent work [29] has reported high-brightness probes may quickly damage 14YWT specimens thinner than $15 \mathrm{~nm}$.

Besides hardware advances, new data analysis methodologies [30-32] based upon multivariate statistical analysis (MVSA) allow deeper insight to be obtained from the statistical dimensionality reduction of large SI datasets. Most relevant to the present discussion, as discussed in detail by other authors [31], MVSA methods are valuable for finding extremely small area fraction features, sometimes even single pixels, in a large SI dataset, or for noise filtering to aid quantitative analysis in STEM-EDS SI data [33-36].

In this paper, we review analyses of as-fabricated 14YWT NFA performed with the latest-generation AEM are compared to those obtained from a conventional AEM experiment. It will be demonstrated that such hardware advances, coupled to modern data post-processing methods, provide a deeper level of insight for the nanoscale features critical for NFA development.

\section{Experimental}

\subsection{Sample material and preparation}

Specimens of 14YWT material, whose fabrication has been discussed in detail previously [16] were examined. The nominal composition was $\mathrm{Fe}-15$ at. $\% \mathrm{Cr}, 0.6 \% \mathrm{~W}, 0.26 \% \mathrm{Ti}, 0.13 \%$ $\mathrm{Y}, 0.19 \% \mathrm{O}$. The material was mechanically alloyed followed by canning, heating, extrusion, and annealing.

TEM specimens were prepared by a $\mathrm{Ga}^{+}$FIB milling lift-out method [37]. A tungsten cap was deposited as a protective layer, followed by rough milling, specimen lift-out, and final ion thinning. Lift-out specimens were $\sim 5000 \mathrm{~nm}$ square and $\sim 100 \mathrm{~nm}$ thick, which resulted in no appreciable ferromagnetic aberrations of the (S)TEM instruments. Lift-out specimens were mounted to molybdenum grids. Final cleaning was performed with $2-5 \mathrm{keV} \mathrm{Ga}^{+}$at slight taper angles to produce a clean, low-Ga specimen with thin regions near the bottom and more uniform, slightly thicker regions near the top. Because of the Mo grid, spurious Mo counts are seen in all X-ray spectra of this Mo-free alloy and should be ignored. 


\subsection{AEM experiments}

A Philips/FEI CM200 field-emission TEM/STEM was used for the conventional AEM studies. The EDS detector is an EDAX $\mathrm{Si}(\mathrm{Li})$-type detector with estimated solid angle of collection of $\sim 0.1$ srad. EELS and EFTEM were performed with a Gatan GIF200 image filter. Beam control was via Gatan Digiscan II hardware and Digital Micrograph software, and allowed simultaneous acquisition of EDS+EELS spectrum images (SI). The operating voltage was 197 $\mathrm{keV}$. An FEI Tecnai Osiris high-brightness field-emission TEM/STEM was used for the advanced AEM studies. The EDS detector was the FEI Super-X detector, consisting of four SDD chips for a total active area of $120 \mathrm{~mm}^{2}$ and $\sim 0.9 \mathrm{srad}$ solid angle of collection. Also used was an FEI FS-1 PEELS (parallel electron energy loss spectroscopy) unit and an operating voltage of 200 kV. Fast-mapping EDS spectrum images were acquired using Bruker Quantax software, whereas EDS+EELS spectrum images were acquired using FEI TIA software. Scan and beam parameters are described with the associated datasets below.

All SIs were acquired with active drift compensation, and probe and scan parameters are listed with the associated datasets.

\section{$\underline{2.3 \text { Multivariate statistical analysis }}$}

Multivariate statistical analysis (MVSA) of EDS SIs was performed with methods described previously [31, 33, 38-40]. Briefly, the SI data is scaled for Poisson noise and the small number of linearly independent pairs of image components (scores) and spectral components (loadings) that best describes the data in a low-rank fashion is determined. These scores and loadings are returned to physical space from the noise-scaled space, and the matrix rotations are applied to maximize the spatial-domain contrast to aid interpretability.

\section{Results}

\subsection{Direct comparison}

Results of combined EDS+EELS spectrum images acquired on the conventional AEM are shown in Figure $2 \mathrm{a}$ and the experimental conditions are given in Table 1. The sample regionof-interest showed a grain boundary nearly edge-on to the beam, along with several small Ti-Y NCs. The simultaneously acquired high-angle annular dark field (HAADF ) STEM image shows mottled contrast, the origin of which is not known for certain, but it is hypothesized that this results from electron beam damage to the oxidized layers on the top and bottom of the FIB foil. The data acquired on the Advanced AEM are shown in Figure 2b [9], and the experimental conditions are also given in Table 1. The sample region-of-interest for these analyses also showed a grain boundary nearly edge-on to the beam, along with several small Ti-Y precipitates and a large $\operatorname{Ti}(\mathrm{O}, \mathrm{C}, \mathrm{N})$ precipitate at the bottom-center. The simultaneously acquired annual dark field (ADF) STEM image shows no specimen damage, as a result of a $40 \%$ lower probe current (500 pA vs. $1300 \mathrm{pA})$.

Although the aggregate number of electrons per pixel in the Osiris data is $\sim 38 \%$ of that for the CM200, the EDS and EELS data are much clearer (compare Figure 2a and 2b) as a result of improved detection hardware and a probe size that is smaller than the pixel size, whereas the probe size in the conventional case was approximately twice the pixel size. The mean X-ray 
counts/pixel were $\sim 1700$ in the advanced case data (or $\sim 4,000$ counts/sec) and only $\sim 760$ counts/pixel $(\sim 1500$ counts/sec) in the conventional case. In terms of counts per unit time per unit current, the advanced case showed a factor of $\sim 2-3$ improvement, the net result being the vastly improved EDS and EELS data (the $\sim 7 \times$ factor expected from solid angle differences should not be expected in practice, because the thicknesses of the examined regions are different).

Due to the near-overlap between the O-K $(\sim 532 \mathrm{eV})$ and $\mathrm{Cr}-\mathrm{L}_{2,3}(\sim 574 \mathrm{eV})$ EELS edges, the Cr EELS data in both figures must be considered carefully. The high X-ray signal in the advanced case dataset allows improved confidence in the $\mathrm{Cr}$ mapping. For instance, a slight $\mathrm{Cr}$ rich ring surrounds one of the Ti-Y rich particles (designated by arrow in Figure 2b), confirming an EFTEM result noted by de Castro et al. [41] and EDS results noted by Certain et al. [42]. Nitrogen is difficult to detect by EDS, particularly in the presence of Ti due to the near-overlap of the N-K and Ti-L X-ray lines, but the EELS data differentiates them clearly, as seen in Figure $2 b$.

Single-pixel point spectra are extracted from the two points (across grain boundaries denoted as "i" and "ii") in the EDS and EELS SIs shown in Figure 2, and each are presented in Figure 3. The advanced AEM EDS spectrum shows a much higher signal-to-noise ratio, and lowlevel elemental signals for Y and Ti are clearly visible, in contrast to the conventional AEM EDS spectrum. The signal-to-noise ratio in the EELS data is somewhat higher in the conventional AEM, likely due to the larger number kof incident electrons per pixel in that dataset (EELS systems have an inherently high collection efficiency [24]). However, both EELS spectra contain the same information, specifically Ti-L, O-K, Cr-L, and Fe-L peaks. These detailed microstructural analyses provide insight into the grain boundary structure and chemistry, which is vital to understand the remarkable creep properties of NFAs.

\subsection{Large area mapping}

The ability, in advanced AEMs, to obtain high count rates from a thin specimen allows for the acquisition of elemental maps from large areas in reasonable times. A large mapped region is shown in Figure 4, with the associated experimental conditions given in Table 2. The mean stored count rate was $\sim 10^{5} \mathrm{X}$-rays/s $\left(\sim 4.4 \times 10^{7}\right.$ total counts over $\left.\sim 396 \mathrm{~s}\right)$. Count values are in the truncated range 0.24 to $19.52 \mathrm{keV}$. A HAADF-STEM image and Fe-K $\alpha, \mathrm{Cr}-\mathrm{K} \alpha$, Ti-K $\alpha$, $\mathrm{W}-\mathrm{L} \alpha$, and $\mathrm{Y}-\mathrm{K} \alpha \mathrm{X}$-ray count maps are shown (note that the bottom few rows of pixels are $\mathrm{W}$ rich from the $\mathrm{W}$-capping layer used during FIB sample preparation). Also note the small features labeled "1" and "2" in Figure 4, which are discussed below. Beam current is estimated at several nA, but was not recorded.

MVSA data reduction was applied to the SI shown in Figure 4, and the result is shown in Figure 5. Five non-noise components are identified via MVSA, and the image/spectrum pairs are plotted in Figure 5. The first two components (rows) describe the matrix. The ratios of K to L Xray lines are different in the two spectral loadings, and the locations of the two components are seen to be approximately complementary in the score images. In particular, the first component has a high contribution from the low-energy $\mathrm{Cr}$ and Fe L-lines, and is more strongly present in the FIB-curtained area near the large pore; curtaining is a FIB artifact where thickness variations develop parallel to the $\mathrm{Ga}^{+}$-beam direction, and is common in multiphase materials. This is a classical signature of absorption differences or other non-linear contributions detected by MVSA 
[31], and in this case results from variations in FIB specimen thickness. It also implies this specimen region was somewhat thick (estimated $\sim 100-200 \mathrm{~nm}$ ), which aids in achieving the high count rates.

The third MVSA component in Figure 5 shows Y, O, and Ga contributions in the spectral domain and is spatially at the pore, indicating a combination of oxidation and uncontrolled Ga+ implantation at the surface of the pore during FIB milling. Because the SDD detectors are windowless, the $\mathrm{O} X$-rays have good detectability in this experiment.

The fourth MVSA component shows strong Ti-K and Ti-L lines; in principle, with the windowless detector $\mathrm{N}-\mathrm{K}$ should be present but the overlap with Ti-L is too close to resolve with any EDS system. These lines correlate with the observed high density of Ti-rich particles.

The fifth component is surprising. The designation "1" noted in Figure 4 is repeated on the score image. The loading spectrum shows the expected $\mathrm{Fe}, \mathrm{Cr}$, and $\mathrm{W}$ lines, because the particle "1" is not the full thickness of the foil and the matrix signal is present as well as the precipitate signal. The precipitate contribution is seen to be primarily Al-K, with a strong O-K signal as well. Because Al-rich particles are not hypothesized in this $0.02 \mathrm{wt} \% \mathrm{Al}$ alloy, X-ray region-of-interest maps such as shown in Figures 2 and 4 would not have identified this feature.

For completeness, the $\mathrm{O}$ and $\mathrm{Al}$ maps are presented in Figure 6. Note that $\mathrm{Cr}-\mathrm{L}$ and $\mathrm{O}-\mathrm{K}$ overlap, so any features present in in the $\mathrm{Cr}-\mathrm{K}$ maps (Figure 4) that are also present in the O-K map may be artifacts, such as the particles running horizontally at approximately the mid-point of the $\mathrm{Cr}$ and $\mathrm{O}$ maps, designated "2". Features such as the Al-rich particle, however, are not noted in the Cr-K map but are present in the O-K map, and are therefore likely real. Comparison of the maps for features designated "2" indicate $\mathrm{Cr}$-Ti-rich particles, which are also unexpected but discovered by the advanced AEM mapping.

This analysis illustrates a unique capability and application range previously inaccessible to materials scientists. Mapping such large areas, in order to discover small-volume-fraction features, is impractical using APT or traditional AEM instruments, but a new and exciting capability with advanced hardware. Similarly, although SEM excels at large-area EDS mapping, features of sub-100 $\mathrm{nm}$ scale are generally inaccessible due to spatial resolution considerations in SEM.

\subsection{High resolution mapping}

To determine how fine a level of detail could be obtained by advanced AEM methods, an additional EDS-SI was acquired using the experimental conditions given in Table 3. The map acquisition ran for $\sim 60 \mathrm{~min}$., and over the truncated range 0.32 to $16.53 \mathrm{keV}$, a total of $6.3 \times 10^{7}$ counts were recorded, for $\sim 250$ mean counts/pixel or $\sim 1.7 \times 10^{4}$ stored counts/s. Based upon the data given in Figure 1, and an estimate of the specimen thickness of 50-100 $\mathrm{nm}$ in the region-ofinterest, the spatial resolution can be estimated at $\sim 1 \mathrm{~nm}$. Note that the spatial area examined in this map is $\sim 4 \%$ of the area studied in the map of Section 3.2 above. This data was originally published elsewhere [13], but we now analyze it in more detail.

The bright field (BF) STEM and the Fe, Cr, Ti, W, and Y X-ray maps are shown in Figure 7. The BF-STEM image shows significant diffraction contrast; two grains are in strongly diffracting conditions and appear black in the BF-STEM image. Light-contrast, round features in 
the image coincide with the Ti-rich areas.

The X-ray data also demonstrate the channeling effects in the strongly diffracting grains. Furthermore, the $\mathrm{Cr}, \mathrm{W}$ and $\mathrm{Y}$ signals outline the grain boundaries, showing the solute segregation at the grain boundaries in this material. The capability to determine in a straightforward fashion what fraction of grain boundaries over a large area are enriched in solute is another example of an experiment inaccessible to other methods. For instance, APT can only image obviously-enriched boundaries (although methods under development to provide a crystallographic component to APT data analysis to ameliorate this weakness [43-45]). Further, traditional AEM can examine only a small number of grain boundaries per hour, and SEM does not have the spatial resolution to resolve the $\sim 2 \mathrm{~nm}$ thick solute-enriched regions.

MVSA data analysis (Figure 8) similarly shows two matrix components with differing $\mathrm{Fe}, \mathrm{Cr}-\mathrm{K} / \mathrm{Fe}, \mathrm{Cr}-\mathrm{L}$ ratios. The first $\mathrm{K} / \mathrm{L}$ ratio is $\sim 2$, and the second $\sim 3$, indicating the $\mathrm{Fe}-\mathrm{Cr}-\mathrm{W}$ nature of the matrix and the effect of the strongly diffracting conditions in the two grains that appear dark in the BF-STEM image. The third MVSA component shows elevated $\mathrm{Cr}$ and $\mathrm{W}$ signals compared to the matrix components, and sharply outlines the grain boundaries, indicating that the $\mathrm{Cr}-\mathrm{W}$ enrichment is both present and easily detected under these experimental conditions. The fourth MVSA component appears to track the third spatially, but in fact shows discrete features along the grain boundaries, and indicates $\mathrm{Y}$ and $\mathrm{Ti}$ counts (insets). It should be noted the $\mathrm{Fe} \mathrm{K} \alpha$ escape peak sits at $\sim 4.66 \mathrm{keV}$ compared to $4.51 \mathrm{keV}$ for $\mathrm{Ti} \mathrm{K} \alpha$, and therefore manifests as a shoulder on the $\mathrm{Ti} \mathrm{K} \alpha$ peak. The fifth MVSA component shows the Ti-rich precipitates.

The area designated by the arrow "1" in Figure 7 is a Ti-rich particle; the sum of the pixels within this particle is presented in Figure 9. Strong Ti-K and Ti-L lines are noted, but unfortunately due to the Ti-L/N-K overlap, the presence of $\mathrm{N}$ would require additional EELS analysis to confirm. A very small Al peak may also be present.

The area designated by the arrow "2" in Figure 7 shows an apparently broad boundary region, which is probably a boundary inclined to the electron beam, and indicates a consideration for large-area mapping: quantification of the grain boundary elemental makeup requires that the grain boundary be precisely aligned edge-on along the beam, or may be curved in three dimensions, so when many boundaries are present, not all will simultaneously be suitable for such analysis.

Although this MVSA data analysis does not identify any Al-rich particles, an Al X-ray map, Figure 10 right, indicates some small Al-rich regions, and Figure 10 left shows the sum spectrum from the region designated by an arrow. The lack of an Al-rich MVSA component is probably due to the smaller size of the particles in this sample region. It is likely that if the data were re-collected with a longer integration time, the Al-rich regions would appear in an MVSA analysis. As noted elsewhere, the ability of MVSA to find a given component depends on many contributions, primarily signal to noise [34, 35, 40, 46].

\section{Discussion}

The above datasets indicate the superior capabilities of a modern AEM instrument. A comparison with older-generation AEM data (discussed above) indicates that high spatial resolution experiments using combined EDS+EELS data generation are greatly improved. In 
particular, increased collection efficiency allows more data to be collected with a lower electron dose per pixel. Even in radiation-tolerant materials such as 14YWT, the high intensity (higher dose) of a conventional FEG-STEM probe damaged the material (Figure 2a). For beam sensitive materials, e.g., nuclear-relevant examples being hollandites or glasses for high-level waste disposal, TEM or STEM analysis can cause sufficient damage to the specimen to make data interpretation difficult or suspect [47-52]. Since a detailed science-based understanding of these materials greatly benefits from AEM microstructural analysis, advanced instruments that collect more X-ray counts per incident electron will ameliorate beam-induced artifacts and damage at a given signal-to-noise level.

As both detectors and microscopes continue to improve, such as coupling of large-solidangle detectors to aberration-corrected optics [17, 19,53-55], it is be expected that the ability to measure few atoms of solute at sub-nm resolution will become routine, at least in materials where sample preparation methods allow for the full capabilities of the AEM to be brought to bear. Although detection limits and spatial resolutions may never match the ultimate capabilities of APT, such AEM instruments improve the correlative capabilities of STEM and APT, thereby allowing the advantages of STEM and TEM such as diffraction contrast imaging, grain boundary misorientation measurements, etc., to be applied together with the elemental mapping on the same specimen, $\underline{\text { in situ. }}$.

\section{Conclusions}

The microstructural analysis of 14YWT NFA in conventional and advanced latestgeneration AEM tools has been compared. Modern high-brightness, high-X-ray collection AEM instruments are capable of enabling advanced experiments, such as simultaneous EDS+EELS spectrum imaging at $\mathrm{nm}$ to sub-nm resolution, that are now well-established for the study of nuclear materials. With such improved capabilities, these studies can be performed with simultaneously lessened radiation dose to the specimen and improved X-ray statistics, and can easily be performed at significantly higher spatial resolution.

The ability to collect tens or hundreds of thousands of X-ray counts per second at STEM spatial resolution will revolutionize high-resolution materials analysis. Large area maps are shown to compare favorably to SEM X-ray mapping, allowing comparable count rates (for small scans) at superior resolution. High-resolution fast-mapping provides highly detailed views of the NFA microstructure, superior to conventional AEM analysis and complementing APT datasets.

\section{Acknowledgements}

This research was sponsored by the Materials Sciences and Engineering Division, Office of Basic Energy Sciences, US Department of Energy. Tecnai Osiris STEM usage courtesy of Dr. J. Caola, Dr. C. Henry, and Dr. L. Fu, FEI Company, Hillsboro, OR. Sample material is courtesy of Dr. D. T. Hoelzer, ORNL. Research on CM200 TEM was conducted at the Center for Nanophase Materials Sciences, which is a DOE Office of Science User Facility. 


\section{Appendix A: spatial resolution calculations}

The spatial resolution of EDS in STEM is calculated assuming a Gaussian beam profile at the incident surface of the sample and a Gaussian beam-broadening effect, added in quadrature. The beam broadening term assumes single-scattering and no crystallographic effects [56]:

$$
b=7.21 \times 10^{5} \frac{Z}{E_{0}}\left(\frac{\rho}{A}\right)^{1 / 2} t^{3 / 2}
$$

where $\mathrm{Z}$ is the atomic number of the target, $\mathrm{A}$ its atomic mass, $\rho$ its density $\left(\mathrm{g} / \mathrm{cm}^{3}\right), \mathrm{t}$ the thickness of the specimen $(\mathrm{cm})$, and $\mathrm{E}_{0}$ the primary beam energy $(\mathrm{eV})$. In the calculations here, $\mathrm{Z}=26, \mathrm{~A}=56, \rho=7.8 \mathrm{~g} / \mathrm{cm}^{3}$, and $\mathrm{E}_{0}=200,000 \mathrm{eV}$. Thus, $\mathrm{b}$ has units $\mathrm{cm}$. The broadened beam diameter $\mathrm{R}$ at the exit of the foil is given by $[24,57,58]$ :

$$
R=\sqrt{d^{2}+b^{2}}
$$

Here, $\mathrm{d}$ is the beam diameter $(\mathrm{cm})$ and $\mathrm{R}$ also has units $\mathrm{cm}$. A more appropriate metric is the mid-point broadening value $\mathrm{R}_{\text {mid }}$ :

$$
R_{\text {mid }}=\frac{d+R}{2}
$$

This is the value used in the calculations above. It should be noted that Michael et al. [57] suggest a value that is equal to $R_{\text {mid }} / \sqrt{2}$ when $R_{\text {mid }}$ is defined as eq. A.3. This is appropriate when interested in the case of a planar interface, and scattering parallel to the plane is not relevant, e.g., a linescan across a grain boundary. Since the experiments in this paper are maps of arbitrarily shaped features, the factor of $\sqrt{ } 2$ is not used.

For the calculations shown in Figure 1b, these assumptions are made: and the advanced instrument is assumed to have $5 \times$ brighter source and $\sim 7 \times$ higher X-ray collection efficiency than the conventional instrument. Here, it is assumed that for a given probe current, the new instrument applies a $\sqrt{5}$ smaller probe diameter for the same current, and a $7 \times$ thinner sample can be used to achieve the same count rates.

It is also important to caution that these spatial resolution calculations make many assumptions, primarily single scattering and no crystalline channeling effects [24, 56-58], and should be taken as general trends and not exact values. However, a comparison of experimental results with Monte Carlo simulations have shown surprisingly high accuracy [57-60]. Recent work [61] on aberration-corrected instruments has shown significant beam broadening and reduced EDS spatial resolution, especially in comparison to EELS or APT. The values quoted in that study, however, were acquired using a typical EDS collection solid angle ( $\sim 0.18 \mathrm{srad})$ and a relatively thick specimen $(120 \pm 10 \mathrm{~nm})$. It is likely that with thinner specimens enabled by higher collection efficiency, the spatial resolution afforded by the probe-corrected instrument could be used more efficaciously. 
Tables

Table 1: EDS+EELS mapping conditions. SI time does include overhead such as EELS CCD readout time.

\begin{tabular}{cccccccc}
\hline Tool & $\begin{array}{c}\text { Beam current } \\
\text { (est.) } \\
\mathrm{pA}\end{array}$ & $\begin{array}{c}\text { Beam size } \\
\text { (est.) } \\
\mathrm{nm}\end{array}$ & $\begin{array}{c}\text { SI } \\
\text { pixels }\end{array}$ & $\begin{array}{c}\text { SI } \\
\text { size } \\
\mathrm{nm}\end{array}$ & $\begin{array}{c}\text { pixel } \\
\text { size } \\
\mathrm{nm}\end{array}$ & $\begin{array}{c}\text { Pixel } \\
\text { time } \\
\mathrm{ms}\end{array}$ & $\begin{array}{c}\text { SI time } \\
\text { (approx.) } \\
\text { s }\end{array}$ \\
\hline $\begin{array}{c}\text { CM200 } \\
\text { Tecnai }\end{array}$ & 1300 & 2 & $49 \times 49$ & $49 \times 49$ & 1 & 500 & 1800 \\
Osiris & 500 & 0.3 & $50 \times 50$ & $50 \times 50$ & 1 & $100 / 500^{*}$ & 1900 \\
\hline
\end{tabular}

*: Dwell time requested $100 \mathrm{~ms}$, actual dwell times including readout delays: EELS $100 \mathrm{ms,}$ and EDS 500 ms.

Table 2: Large area mapping conditions

Beam current (est.) $\quad$ Beam size (est.) $\quad$ SI pixels $\quad$ SI size (approx.) $\quad$ pixel size $\quad$ Pixel time $\quad$ SI time (approx.)

\begin{tabular}{|c|c|c|c|c|c|c|}
\hline $\mathrm{nA}$ & $\mathrm{nm}$ & & $\mathrm{nm}$ & $\mathrm{nm}$ & $\mathrm{ms}$ & $\mathrm{s}$ \\
\hline $1-10$ & $\sim 5$ & $400 \times 400$ & $2630 \times 2630$ & $\sim 6.5$ & $\sim 2.5$ & 396 \\
\hline
\end{tabular}

Table 3: High resolution mapping conditions

\begin{tabular}{cccccccc}
\hline $\begin{array}{c}\text { Beam current (est.) } \\
\mathrm{nA}\end{array}$ & $\begin{array}{c}\text { Beam size (est.) } \\
\mathrm{nm}\end{array}$ & SI pixels & $\begin{array}{c}\text { SI size (approx.) } \\
\text { pixel size }\end{array}$ & $\begin{array}{c}\text { Pixel time } \\
\mathrm{nm}\end{array}$ & SI time (approx.) \\
\hline 1.5 & 1 & $500 \times 500$ & $500 \times 500$ & 1 & $\sim 14$ & 3600 \\
\hline
\end{tabular}




\section{Figures}

Figure 1: (a) Plot of EDS spatial resolution for iron as a function of probe size and specimen thickness. (b) Relationship between potential spatial resolution with increasing detection efficiency and source brightness. Appendix A defines b, d, t, R, and $\mathrm{R}_{\text {mid }}$, calculations, and input parameters. Adapted from Parish and Miller [19]. Copyright Microscopy Society of America, 2014, Reprinted with permission from Cambridge University Press.

Figure 2: comparison of CM200 AEM data (a) to Osiris AEM data (b). CM200 conditions: $\sim 1300 \mathrm{pA}, \sim 2 \mathrm{~nm}$ probe, $49 \times 49$ pixels, $500 \mathrm{msec} / \mathrm{pix}, 1 \mathrm{~nm} / \mathrm{pix}, \sim 30 \mathrm{~min}$ total. Osiris conditions: $\sim 500 \mathrm{pA}, \sim 0.3 \mathrm{~nm}$ probe, $50 \times 50$ pixels, $\sim 500 \mathrm{msec} / \mathrm{pix}, 1 \mathrm{~nm} / \mathrm{pix}, \sim 30 \mathrm{~min}$ total. Data in (b) adapted from Miller and Parish [9].

Figure 3: Single-pixel SI point spectra (EDS and EELS) from the data presented in Figure 2. Inset STEM images are size $\sim 50 \times 50 \mathrm{~nm}$ and arrows indicate the approximate points from which the EDS and EELS spectra are extracted.

Figure 4: 400×400 pixel X-ray map taken in $396 \mathrm{sec}$ at $\sim 10^{5}$ counts/sec. Features, including pores, Ti-rich, Cr-rich, and Y-rich particles are observed.

Figure 5: MVSA analysis of SI presented in Figure 4. Five major contributions were found. In the fifth independent component, an Al-O rich particle is identified (arrow "1").

Figure 6: Al-K and O-K maps extracted from the Figure 4 and Figure 5 SI dataset.

Figure 7: X-ray maps and BF-STEM image for 500×500 pixel, 500×500 nm map with 1500 $\mathrm{pA} \sim 1 \mathrm{~nm}$ probe, acquired over $60 \mathrm{~min}$. Adapted from Miller et al. [13]

Figure 8: MVSA analysis of the SI data shown in Figure 7.

Figure 9: Sum spectrum from Ti-rich particle "1" marked in Figure 7.

Figure 10: Sum spectrum from Al-rich particle (designated by arrow) and Al-K X-ray map.

\section{References}

[1] R. K. Nanstad, D. A. McClintock, D. T. Hoelzer, L. Tan and T. R. Allen, Journal of Nuclear Materials 392(2) (2009) 331-340.

[2] Y. Guerin, G. S. Was and S. J. Zinkle, MRS Bulletin 34(1) (2009) 10-14.

[3] R. L. Klueh, Journal of Nuclear Materials 378(2) (2008) 159-166.

[4] K. L. Murty and I. Charit, Journal of Nuclear Materials 383 (2008) 189-195.

[5] G. R. Odette, M. J. Alinger and B. D. Wirth, Annual Review of Materials Research 38 (2008) 471503.

[6] G. R. Odette and D. T. Hoelzer, JOM 62(9) (2010) 84-92.

[7] V. Badjeck, M. G. Walls, L. Chaffron, J. Malaplate and K. March, Journal of Nuclear Materials 456(0) (2015) 292-301.

[8] J. H. Schneibel, C. T. Liu, M. K. Miller, M. J. Mills, P. Sarosi, M. Heilmaier and D. Sturm, Scripta Materialia 61(8) (2009) 793-796.

[9] M. K. Miller and C. M. Parish, Materials Science and Technology 27(4) (2011) 729-734.

[10] M. J. Alinger, G. R. Odette and D. T. Hoelzer, Acta Materialia 57(2) (2009) 392-406.

[11] J. Bentley, D. Hoelzer, J. T. Busby, A. G. Certain, T. R. Allen, D. Kaoumi, A. T. Motta and M. A. Kirk, Microscopy and Microanalysis 15(Supp. 2) (2009) 1350-1351.

[12] M. K. Miller, K. F. Russell, D. T. Hoelzer, L. Kovarik, M. J. Mills, A. G. Certain and T. R. Allen, Microscopy and Microanalysis 16(Suppl. 2) (2010) 1602-1603. 
[13] M. K. Miller, C. M. Parish and Q. Li, Materials Science and Technology 29(10) (2013) 1174-1178.

[14] M. K. Miller, D. T. Hoelzer and K. F. Russell, Materials Science Forum 654-656 (2010) 23-28.

[15] M. K. Miller, D. Hoelzer and K. F. Russell, Materials Research Society Symposium Proceedings 1215 (2010) V06-02.

[16] M. K. Miller, D. Hoelzer and K. F. Russell, Materials Science Forum 654-656 (2010) 23-28.

[17] C. M. Parish, R. M. White, J. M. LeBeau and M. K. Miller, Journal of Nuclear Materials 445(1-3) (2014) 251-260.

[18] C. M. Parish, P. D. Edmondson, Y. Zhang and M. K. Miller, Journal of Nuclear Materials 418 (2011) 106-109.

[19] C. M. Parish and M. K. Miller, Microscopy and Microanalysis 20(2) (2014) 613-626.

[20] Q. Li, C. M. Parish, K. A. Powers and M. K. Miller, Journal of Nuclear Materials 445(1-3) (2014) 165-174.

[21] P. D. Edmondson, C. M. Parish, Y. Zhang, A. Hallén and M. K. Miller, Journal of Nuclear Materials 434(1-3) (2013) 210-216.

[22] P. D. Edmondson, C. M. Parish, Y. Zhang, A. Hallén and M. K. Miller, Scripta Materialia 65(8) (2011) 731-734.

[23] S. J. Zinkle, G. E. Ice, M. K. Miller, S. J. Pennycook and X. L. Wang, Journal of Nuclear Materials 386-88 (2009) 8-14.

[24] D. B. Williams and C. B. Carter, Transmission Electron Microscopy. (Plenum, New York, 1996).

[25] M. Watanabe, D. W. Ackland, A. Burrows, C. J. Kiely, D. B. Williams, O. L. Krivanek, N. Dellby, M. F. Murfitt and Z. Szilagyi, Microscopy and Microanalysis 12(6) (2006) 515-526.

[26] P. Schlossmacher, D. O. Klenov, B. Freitag and H. S. von Harrach, Microscopy Today July 2010 (2010) 14-20.

[27] H. S. von Harrach, P. Dona, B. Freitag, H. Soltau, A. Niculae and M. Rohde, Microscopy and Microanalysis 16(Suppl. 2) (2010) 208-209.

[28] H. S. von Harrach, D. O. Klenov, B. Freitag, P. Schlossmacher, P. C. Collins and H. L. Fraser, Microscopy and Microanalysis 16(Suppl. 2) (2010) 1312-1313.

[29] M. C. Brandes, L. Kovarik, M. K. Miller and M. J. Mills, Journal of Materials Science 47(8) (2012) 3913-3923.

[30] P. G. Kotula and M. R. Keenan, Microscopy and Microanalysis 12(6) (2006) 538-544.

[31] P. G. Kotula, M. R. Keenan and J. R. Michael, Microscopy and Microanalysis 9(1) (2003) 1-17.

[32] J. M. Titchmarsh and S. Dumbill, Journal of Microscopy-Oxford 184(3) (1996) 195-207.

[33] M. G. Burke, M. Watanabe, D. B. Williams and J. M. Hyde, Journal of Materials Science 41(14) (2006) 4512-4522.

[34] C. M. Parish: Multivariate Statistics Applications in Scanning Transmission Electron Microscopy XRay Spectrum Imaging, in:P. W. Hawkes (ed.), Advances in Imaging and Electron Physics, Vol 168, 2011, Vol. 168, pp. 249-295.

[35] C. M. Parish and L. N. Brewer, Microscopy and Microanalysis 16(3) (2010) 259-272.

[36] C. M. Parish and L. N. Brewer, Ultramicroscopy 110(2) (2010) 134-143.

[37] L. A. Giannuzzi and F. A. Stevie, Micron 30(3) (1999) 197-204.

[38] M. R. Keenan: Multivariate analysis of spectral images composed of count data, in:H. F. Grahn and P. Geladi (ed.), Techniques and Applications of Hyperspectral Image Analysis, John Wiley \& Sons, Chichester, 2007, pp. 89-126.

[39] M. R. Keenan, Surface and Interface Analysis 41 (2009) 79-87.

[40] P. G. Kotula and M. R. Keenan, Microscopy and Microanalysis 9(Supp 2) (2003) 152-153.

[41] V. de Castro, S. Lozano-Perez, E. A. Marquis, M. A. Auger, T. Leguey and R. Pareja, Materials Science and Technology 27(4) (2011) 719-723.

[42] A. G. Certain, K. G. Field, T. R. Allen, M. K. Miller, J. Bentley and J. T. Busby, Journal of Nuclear Materials 407(1) (2010) 2-9.

[43] L. Yao, M. P. Moody, J. M. Cairney, D. Haley, A. V. Ceguerra, C. Zhu and S. P. Ringer, Ultramicroscopy 111(6) (2011) 458-463. 
[44] M. K. Miller and L. Yao, Current Opinion in Solid State \& Materials Science 17(5) (2013) 203-210.

[45] L. Yao, S. P. Ringer, J. M. Cairney and M. K. Miller, Scripta Materialia 69(8) (2013) 622-625.

[46] C. M. Parish, P. D. Edmondson and M. K. Miller, Microscopy and Microanalysis 17(Suppl. 2) (2011) P. 594-595.

[47] K. Sun, L. M. Wang, R. C. Ewing and W. J. Weber, Nuclear Instruments \& Methods in Physics Research Section B-Beam Interactions with Materials and Atoms 218 (2004) 368-374.

[48] K. Sun, L. M. Wang, R. C. Ewing and W. J. Weber, Philosophical Magazine 85(4-7) (2005) 597608.

[49] N. Ollier, B. Boizot, B. Reynard, D. Ghaleb and G. Petite, Journal of Nuclear Materials 340(2-3) (2005) 209-213.

[50] L. A. Bursill and D. J. Smith, Journal of Solid State Chemistry 69(2) (1987) 343-354.

[51] W. J. Weber, R. C. Ewing, C. A. Angell, G. W. Arnold, A. N. Cormack, J. M. Delaye, D. L. Griscom, L. W. Hobbs, A. Navrotsky, D. L. Price, A. M. Stoneham and W. C. Weinberg, Journal of Materials Research 12(8) (1997) 1946-1978.

[52] S. E. Kesson and T. J. White, Proceedings of the Royal Society of London Series a-Mathematical Physical and Engineering Sciences 408(1835) (1986) 295-\&.

[53] D. Klenov, B. Freitag, H. S. von Harrach, A. J. D'Alfonso and L. J. Allen, Microscopy and Microanalysis 17(Suppl. 2) (2011) 598-599.

[54] P. G. Kotula, D. O. Klenov and H. S. von Harrach, Microscopy and Microanalysis 18(4) (2012) 691698.

[55] M. Saber, W. Z. Xu, L. L. Li, Y. T. Zhu, C. C. Koch and R. O. Scattergood, Journal of Nuclear Materials 452(1-3) (2014) 223-229.

[56] S. J. B. Reed, Ultramicroscopy 7 (1982) 405-410.

[57] J. R. Michael, D. B. Williams, C. F. Klein and R. Ayer, Journal of Microscopy 160(1) (1990) 41-53.

[58] D. B. Williams, J. R. Michael, J. I. Goldstein and A. D. Romig, Ultramicroscopy 47(1-3) (1992) 121132.

[59] J. R. Michael, S. J. Plimpton and A. D. Romig, Ultramicroscopy 51(1-4) (1993) 160-167.

[60] S. J. Plimpton, J. R. Michael and A. D. Romig, Journal of Supercomputing 6(2) (1992) 139-151.

[61] A. Genc, R. Banerjee, G. B. Thompson, D. M. Maher, A. W. Johnson and H. L. Fraser, Ultramicroscopy 109 (2009) 1276-1281. 
Click here to download high resolution image

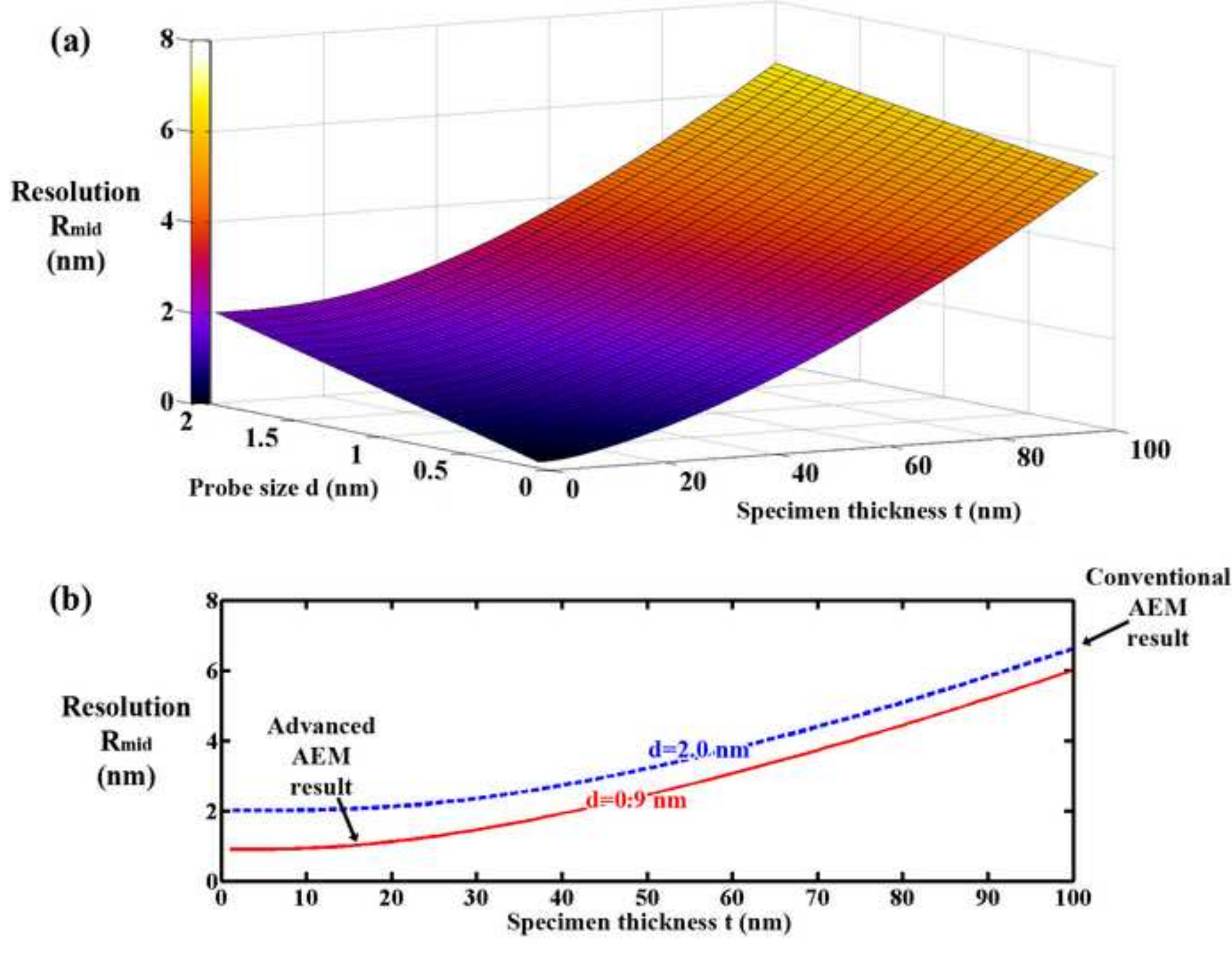

(b)

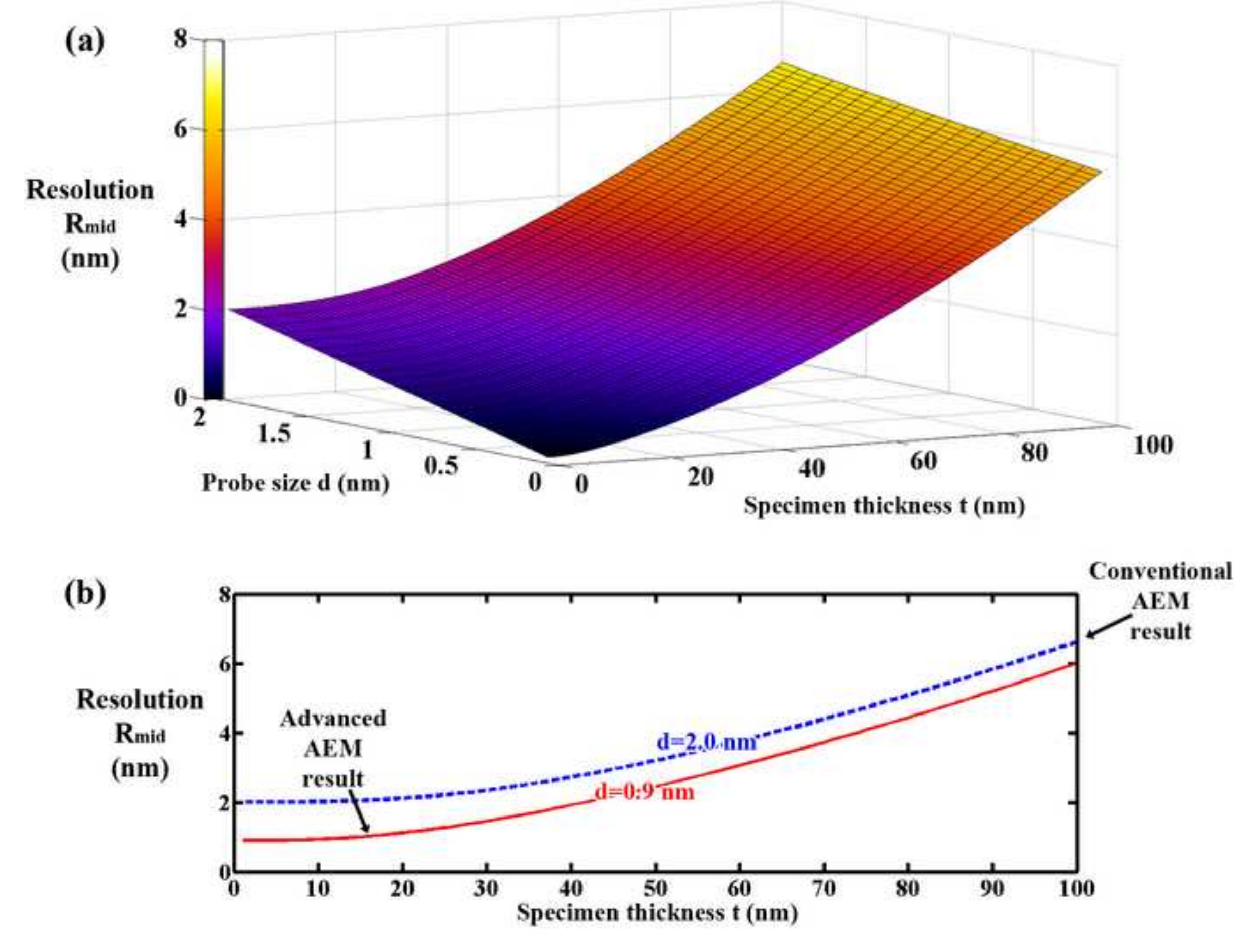

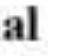

e to download hiah resolution imaas

to 
Click here to download high resolution image

(a)
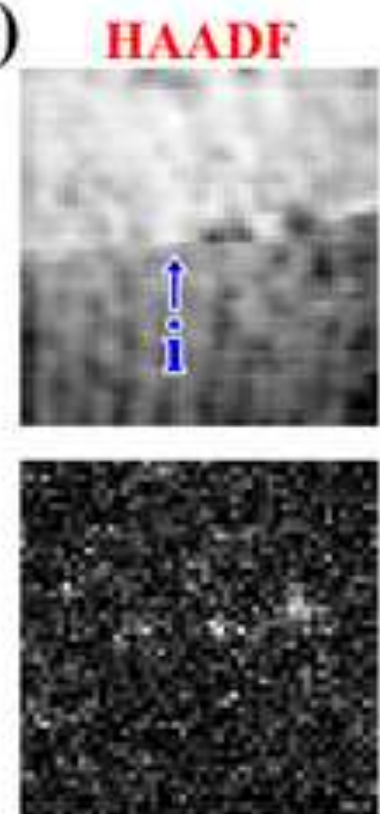

Y EDS

(b)
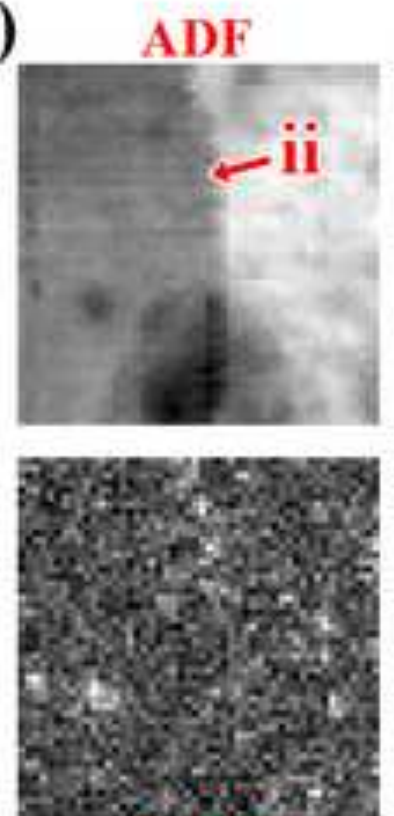

Y EDS
N EELS
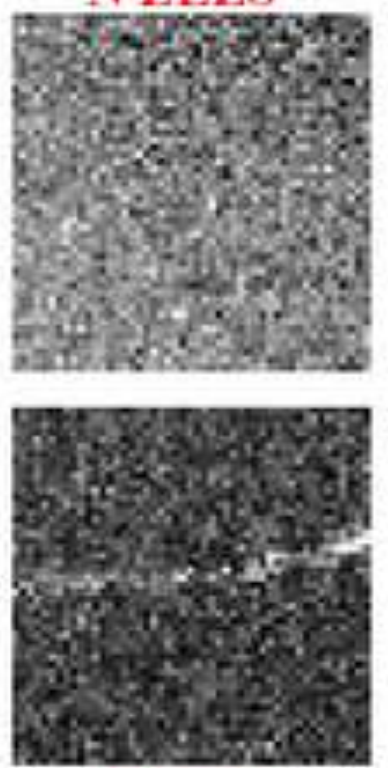

W EDS
Ti EELS
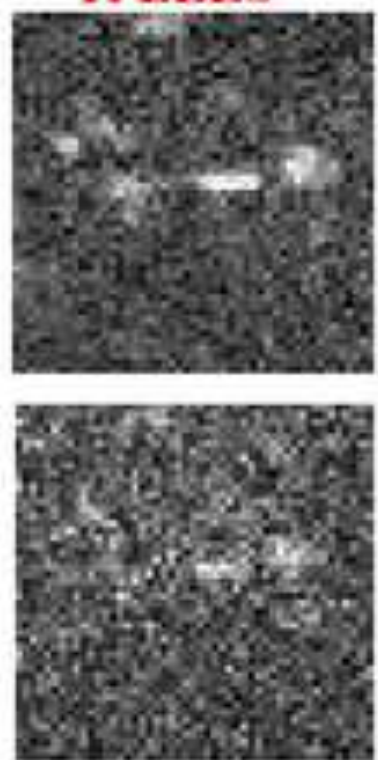

Ti EDS
Cr EELS
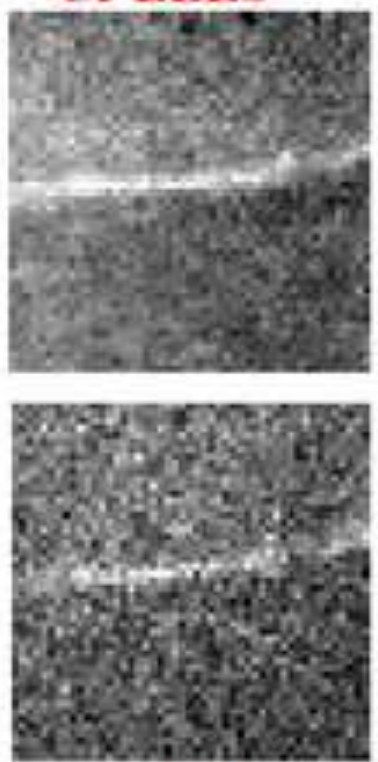

Cr EDS

$50 \mathrm{~nm}$
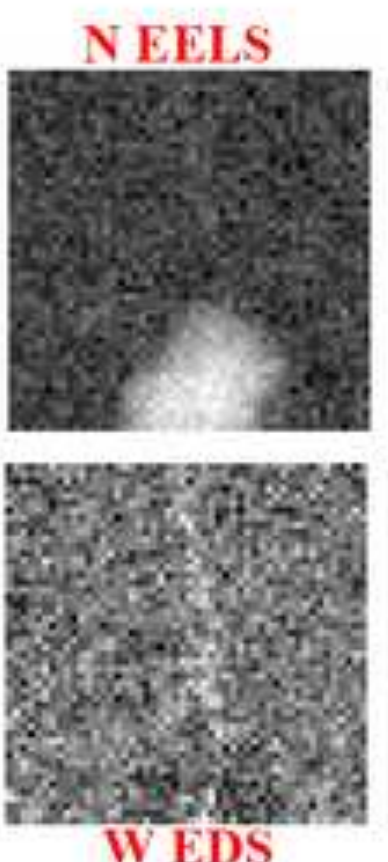

W EDS
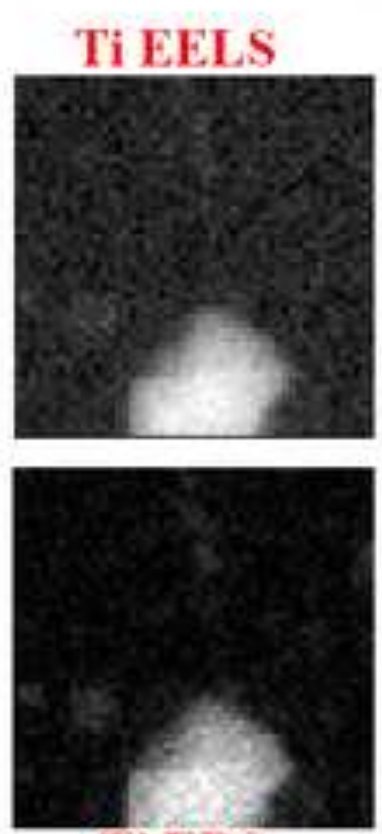

Ti EDS

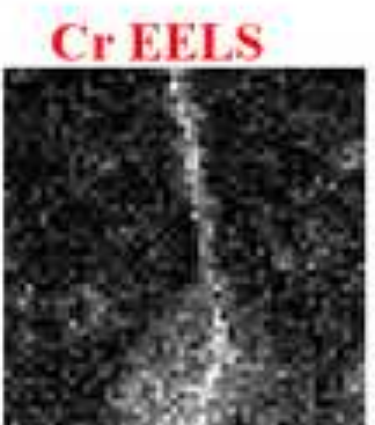

Cr EDS

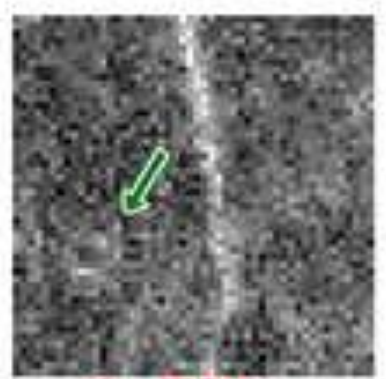

Fe EELS
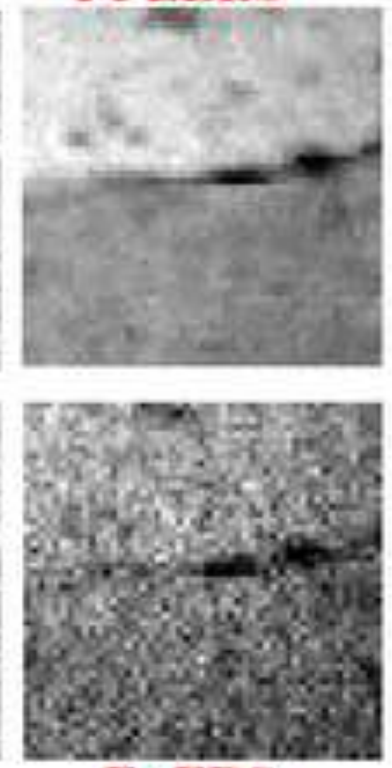

Fe EDS

Fe EELS
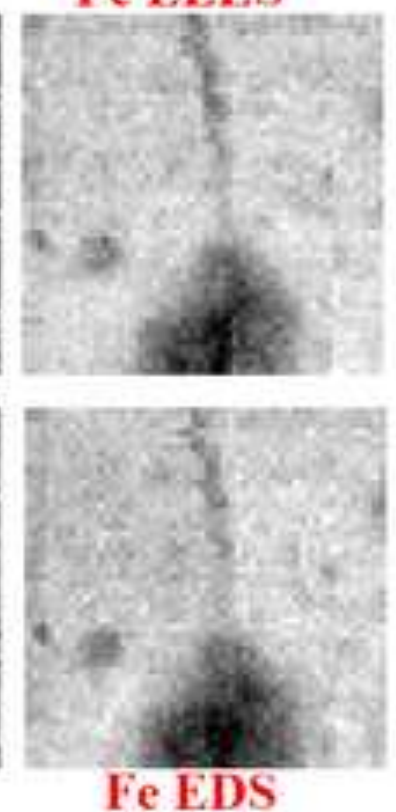

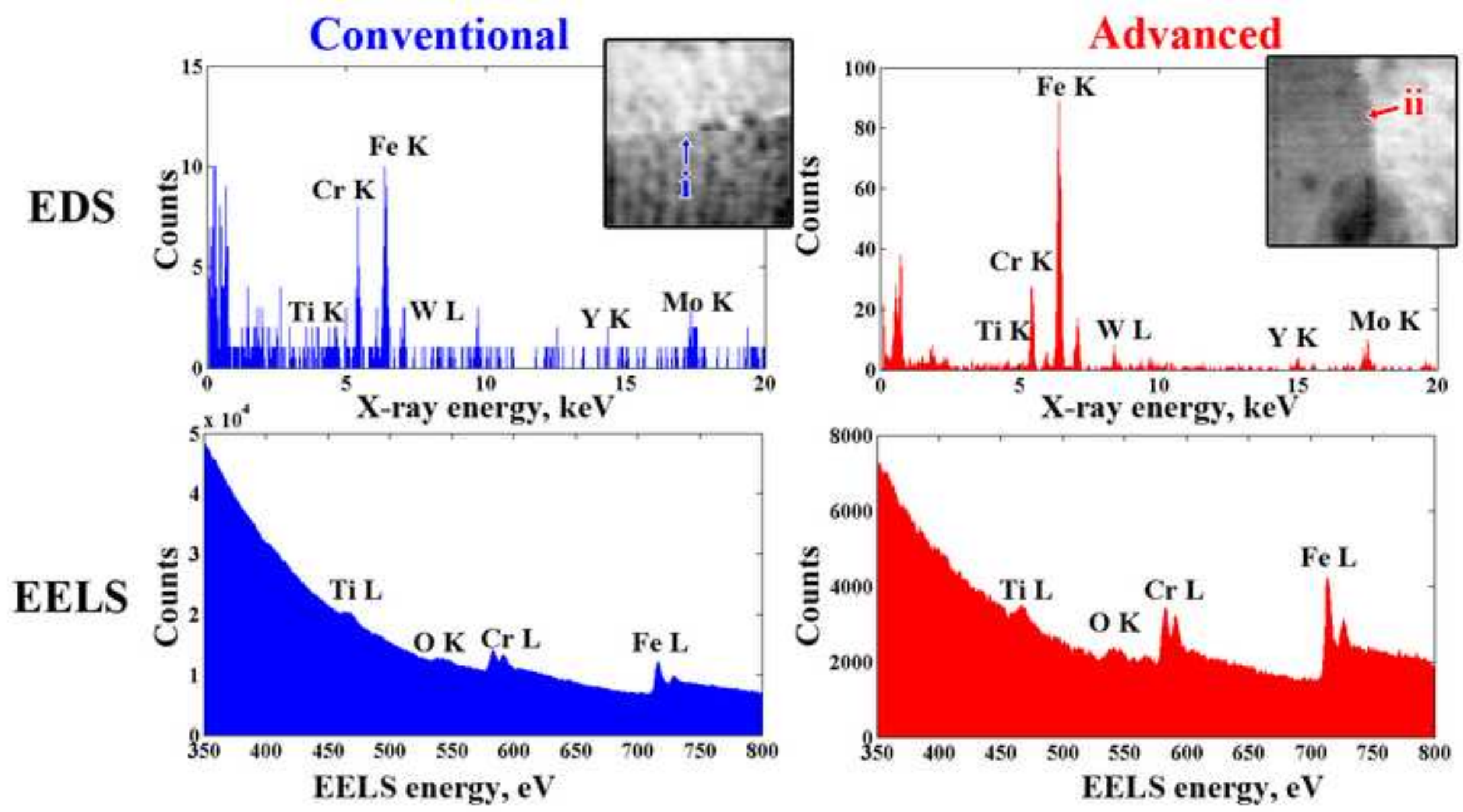

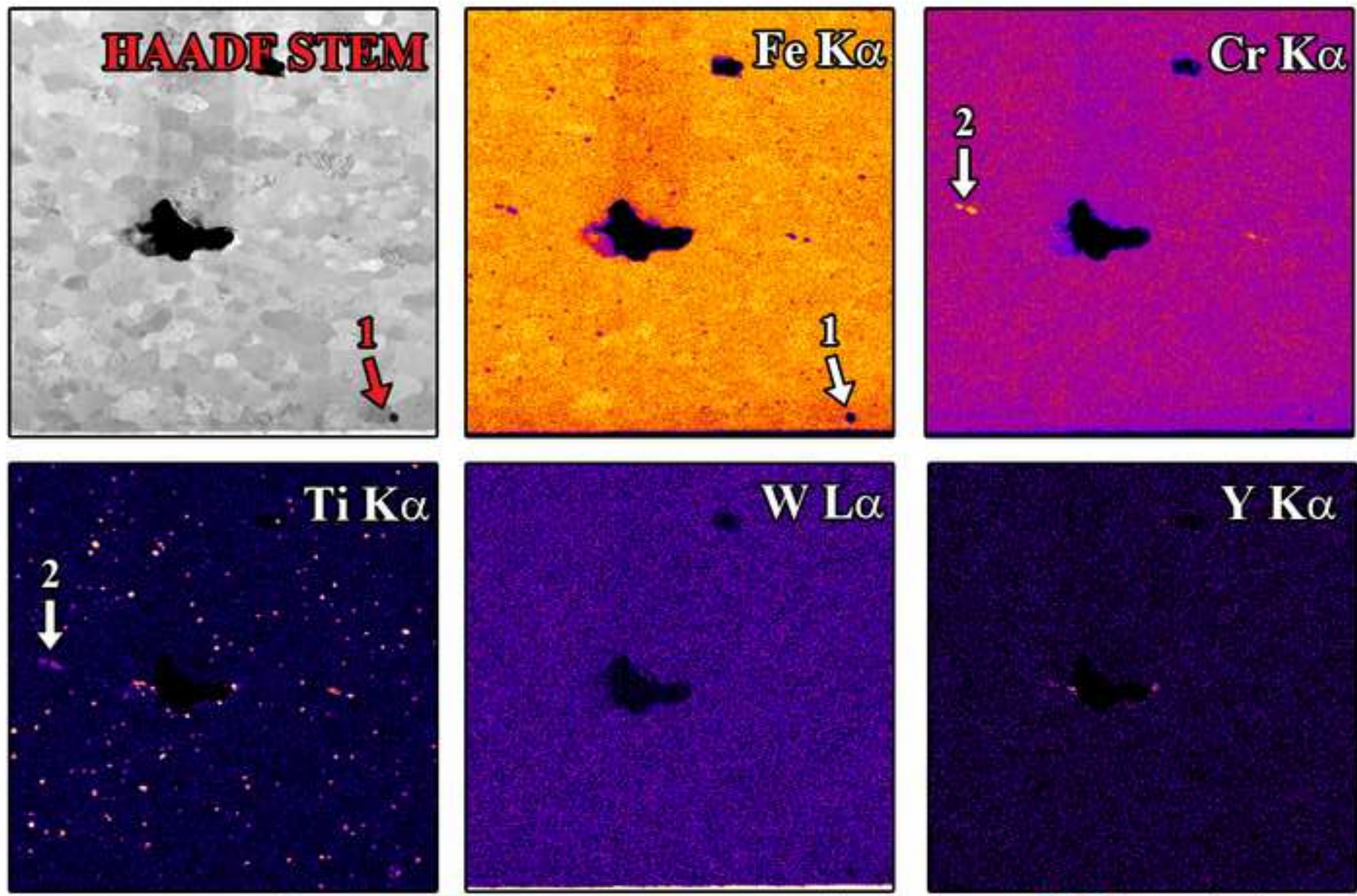

Min

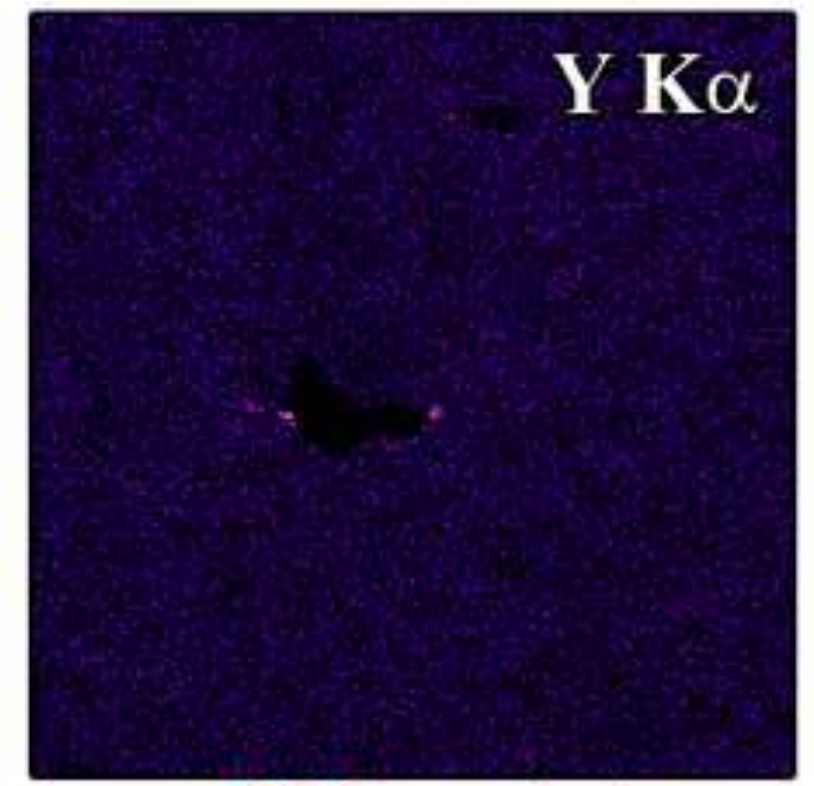

$500 \mathrm{~nm} \longleftrightarrow$ 
Loading spectra

Score images
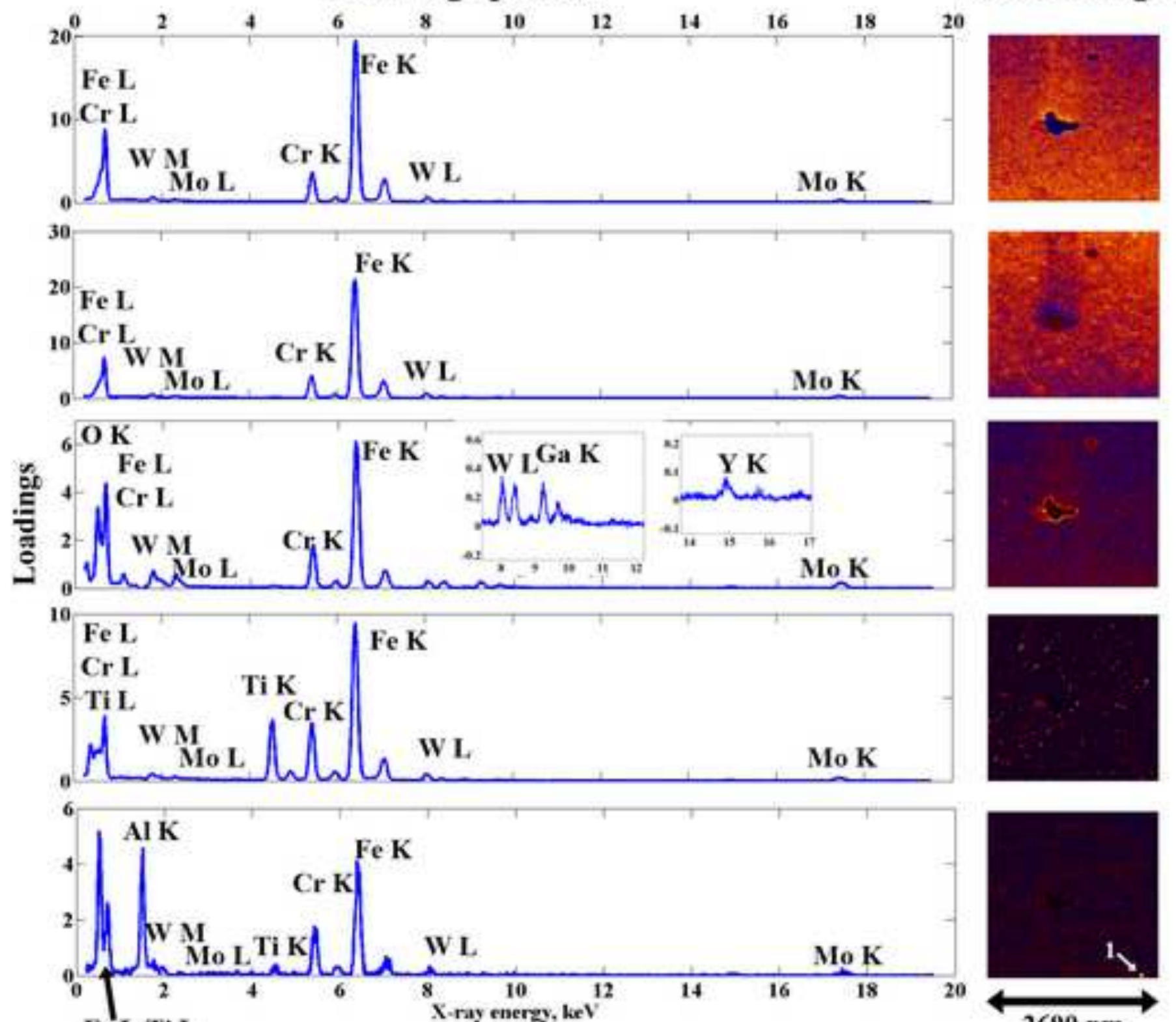

FeL TiL

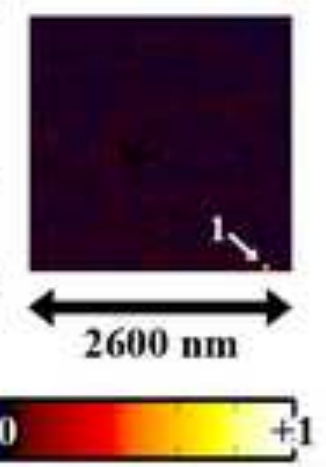

Pixel score 


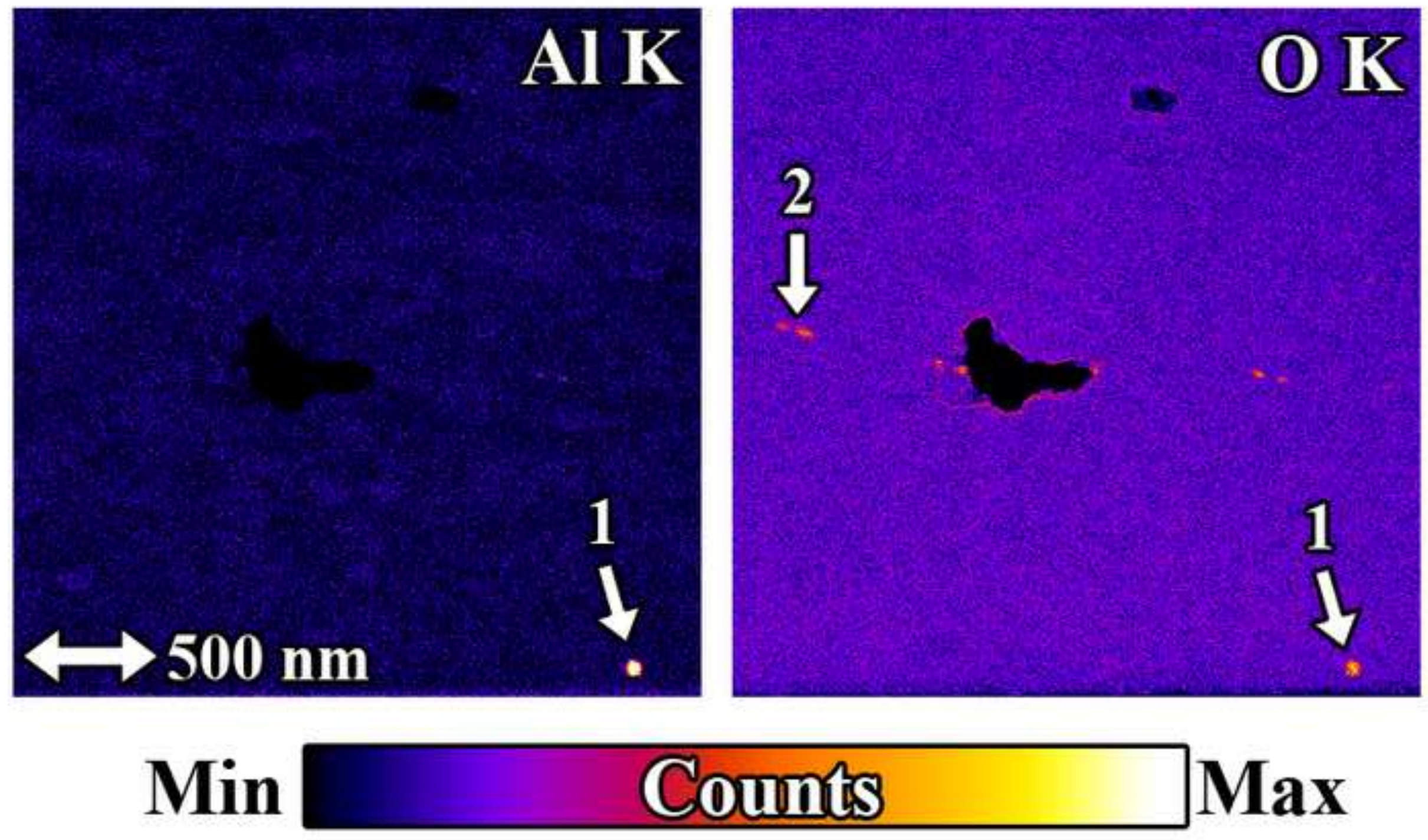



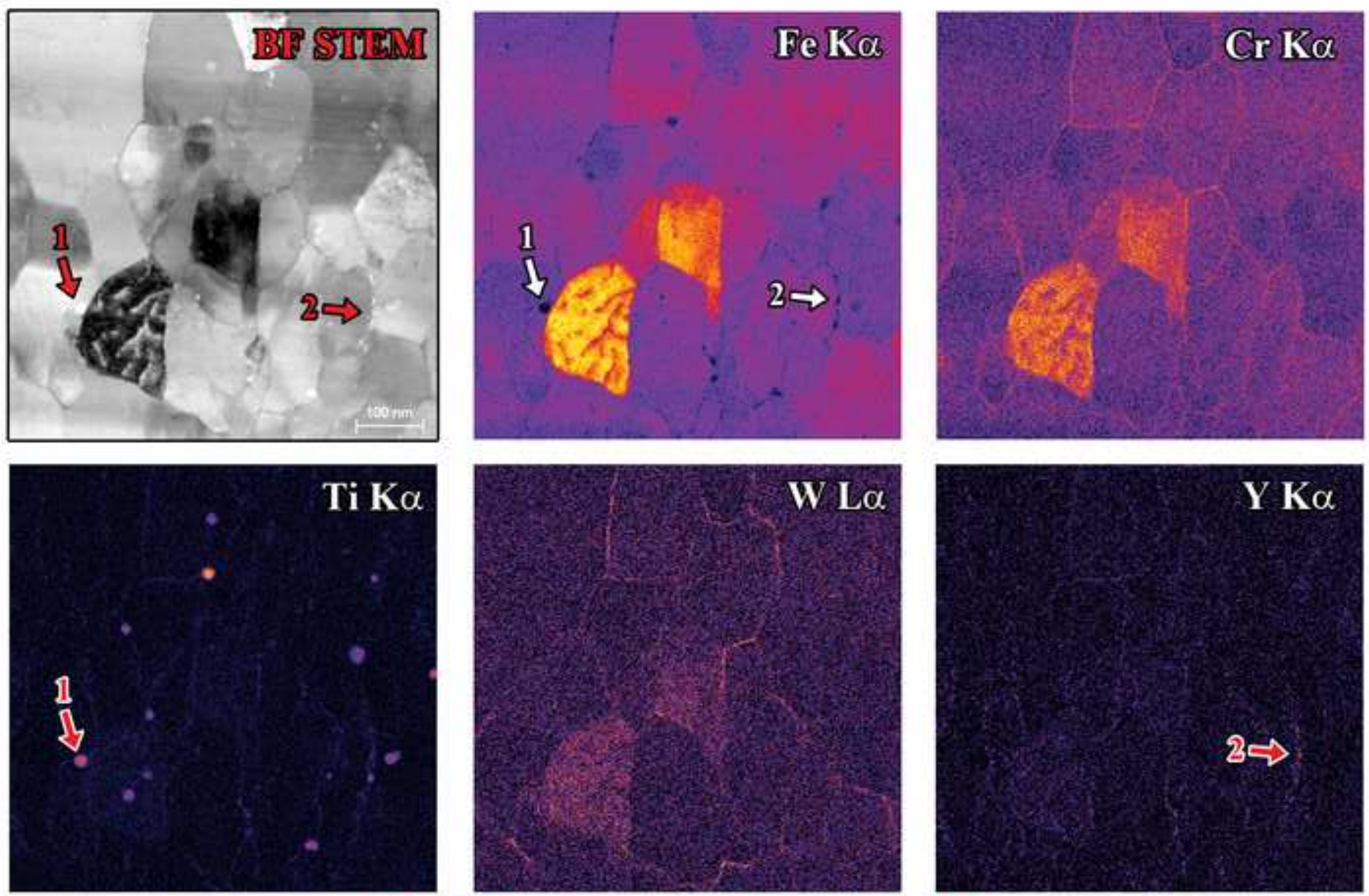

Min

Counts

Max

$100 \mathrm{~nm} \longleftrightarrow$ 


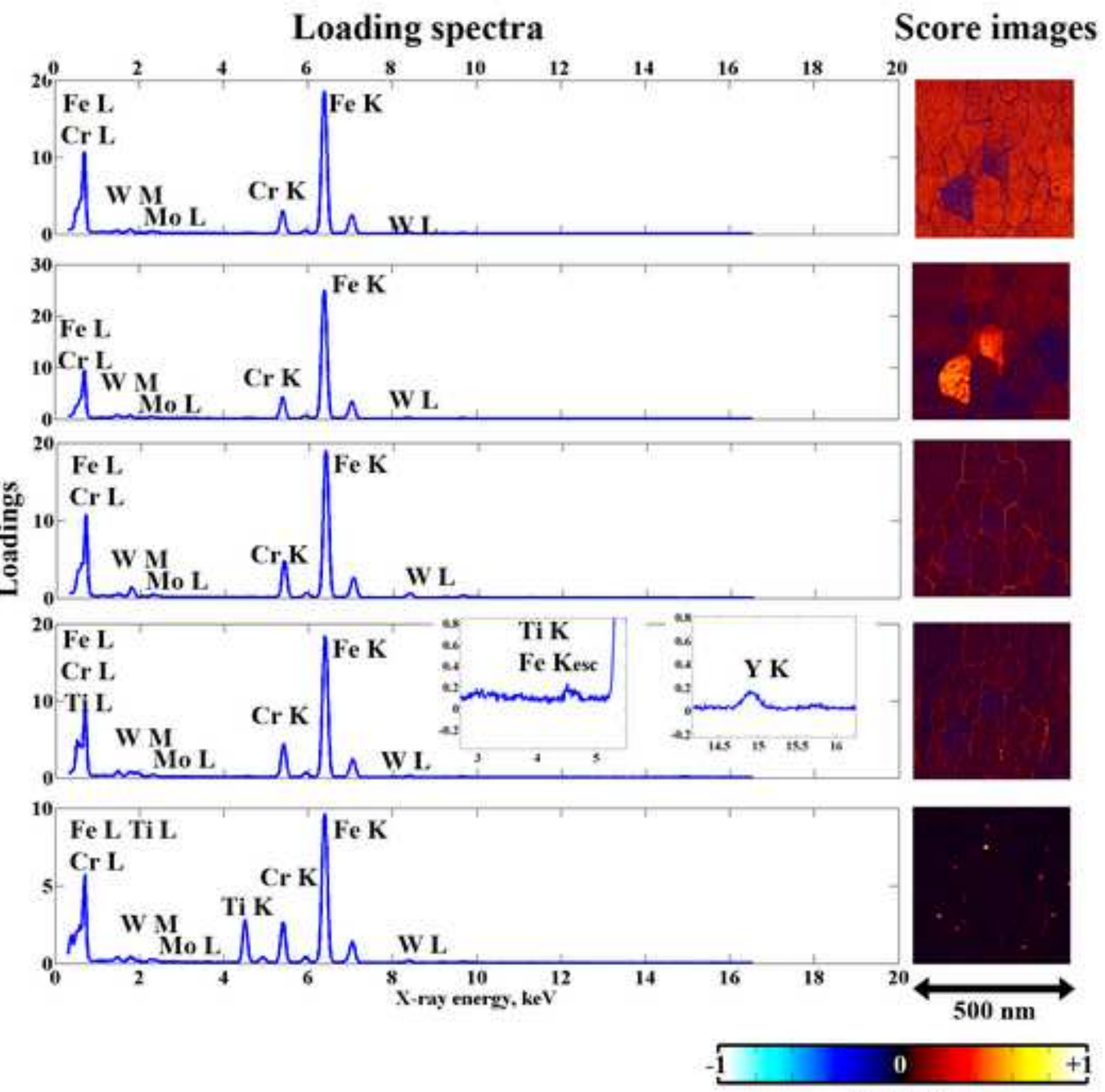

Pixel score 
Figure 9
Click here to download high resolution image

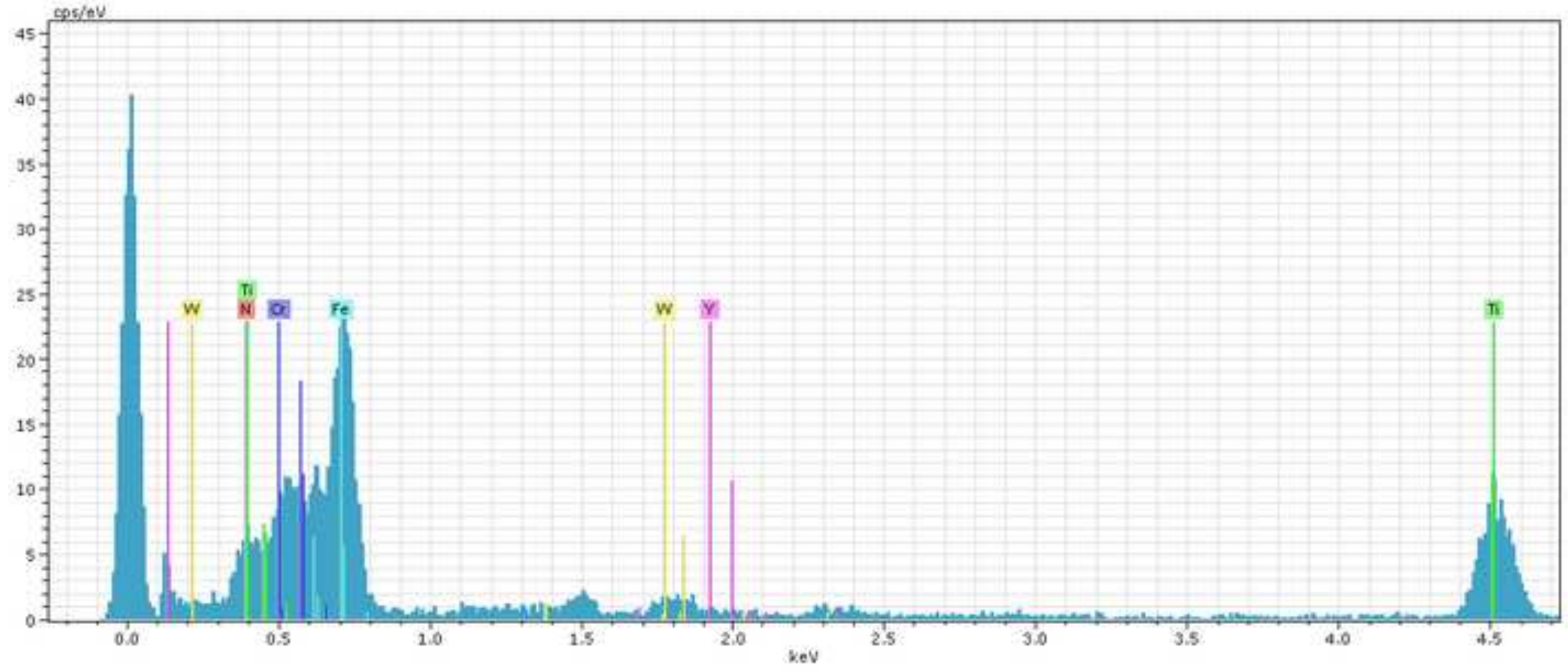


Click here to download high resolution image
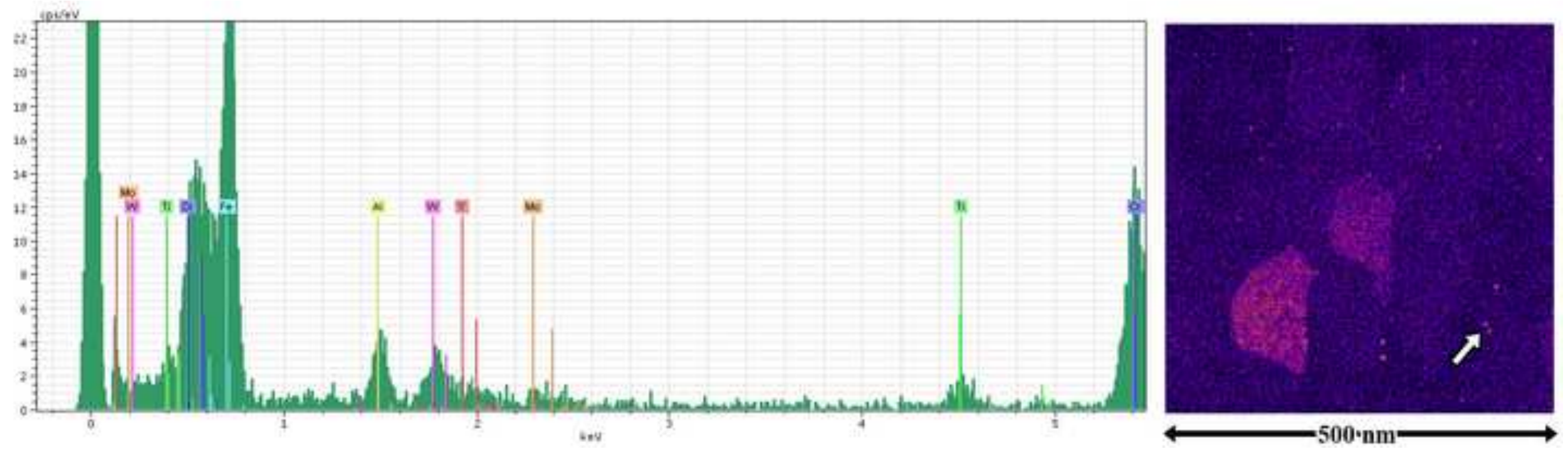

$\operatorname{tn}$ 